\title{
GEOGRAFIA E TURISMO: CONTRADIÇÕES X NOVAS POSSIBILIDADES DE LAZER PARA AS PESSOAS COM DEFICIÊNCIAS FÍSICAS - PCDF'S
}

\author{
Geography and Tourism: contradictions X new possibilities of leisure for \\ people with physical disabilities - PWPD's
}

\author{
Adriana Maria Rodrigues * \\ Cornélio Silvano Vilarinho Neto **
}

* Mestre do Programa de Pós-Graduação em Geografia da UFMT - adrianarodrigues_tur@hotmail.com.

** Docente do Programa de Pós-Graduação em Geografia da UFMT - csvn1943@yahoo.com.

Recebido em 29/06/2019. Aceito para publicação em 30/07/2019.

Versão online publicada em 10/09/2019 (http://seer.ufrgs.br/paraonde)

\begin{abstract}
Resumo:
A produção e reprodução espacial numa cidade se estabelecem por meio da sociedade e espaço geográfico, onde existe essa relação que se torna recorrente, acarretando muitos desafios, conflitos e contradições, e na cidade de Cuiabá isto não é diferente, acontece desde sua colonização e exploração aurífera. As discussões têm acontecido na sociedade por meio de leis e projetos para possibilitar às pessoas com deficiências a inclusão e o acesso aos mais diversos ambientes da cidade em espaços urbanos, tanto públicos como privados, para que possam desenvolver atividades de lazer em consonância com o turismo, estudo, trabalho, outras formas dignas e com acessibilidade. As pesquisas bibliográfica e de campo foram primordiais para o desenvolvimento e alcance dos resultados propostos neste artigo.
\end{abstract}

Palavras-chave: Espaço Urbano, Acessibilidade, Turismo.

\begin{abstract}
:
Production and spatial reproduction in a city are established through society and geographic space, where there is this relationship that becomes recurrent, entailing many challenges, conflicts and contradictions, and in the city of Cuiabá this is no different, since its colonization and gold exploration. The discussions have taken place in society through laws and projects to enable people with disabilities to inclusion and access to the most diverse environments of the city in urban spaces, both public and private, so that they can develop leisure activities in line with tourism, study, work, other dignified forms and with accessibility. The bibliographical and field research were primordial for the development and reach of the results proposed in this article.
\end{abstract}

Key-words: Urban Space, Accessibility, Tourism.

\section{Introdução}

Este trabalho foi desenvolvido a partir das disciplinas e leituras dentro do programa pós-graduação de mestrado em Geografia e surgiu como forma de discutir o direito a acessibilidade e lazer, na busca de ampliar o conhecimento sobre o assunto e garantia dos direitos ao uso de circulação dos espaços da pessoa com deficiência ou com mobilidade reduzida em Cuiabá-MT.

A metodologia foi desenvolvida através de pesquisa bibliográfica e pesquisa de campo, onde as leituras por meio de livros, periódicos, artigos científicos foram primordiais para o embasamento teórico e em campo a observação e registros fotográficos foram essenciais para o desenvolvimento do trabalho e alcance do proposito 
deste artigo.

"A especificação da metodologia da pesquisa é a que abrange maior número de itens, pois responde, a um só tempo, às questões como?, com quê?, onde?, quanto? [...]"(MARCONI; LAKATOS, 2010).

Atualmente, Cuiabá possui aproximadamente 576.855 mil habitantes e uma área territorial de $3.291,816 \mathrm{~km}^{2}$ conforme dados do Instituto de Geografia e Estatística IBGE (2016). A cidade de Cuiabá tem suas origens que advém da sua colonização e principalmente da exploração aurífera que se deu no início do século XVIII, onde "O ouro foi à base econômica para o surgimento tanto da cidade como do estado de Mato Grosso. Mas, é importante ressaltar que a origem da cidade de Cuiabá não foge à regra das demais que surgiram na época da mineração, pois a preocupação das pessoas que vieram para Mato Grosso era a garimpagem de ouro e não a formação de cidade" (VILARINHO 2008, p.16).

As ruas da cidade de Cuiabá eram acidentadas, e com escassez de calçamentos nos logradouros, apesar disso, no final do século XIX os acontecimentos eram realizados no seu cotidiano, eram apreciados pelos cuiabanos, a sua culinária, o andar, o caminhar pelas ruas, o meio de transporte por meio de bondes puxados a tração animal, o apitar da sirene anunciava a chegada do vapor ao porto de Cuiabá e os animais de montaria eram os meios de transporte utilizados no inicio do século XX. No final da década de 1910, os veículos automotivos foram introduzidos na paisagem citadina cuiabana como meio de transporte coletivo. (PINHO, 2007).

A mobilidade urbana constitui-se pelo conjunto de políticas de transporte e circulação; Atributo relacionado aos deslocamentos realizados por indivíduos nas suas atividades na cidade; Condição em que se realizam os deslocamentos de pessoas e cargas no espaço urbano. "Habilidade de movimentar-se, em decorrência de condições físicas e econômicas" (VASCONCELLOS, 2001).

Do ponto de vista metodológico, na relação entre turismo e cidade há de se considerar três possibilidades: a urbanização de dado lugar é precedente ao aparecimento do turismo; é concomitante ou posterior a este. (CRUZ. 2003. p.16).

$\mathrm{Na}$ etapa final foi analisado e interpretado os dados e informações obtidas que proporcionaram as reais problemáticas na cidade de Cuiabá pelos agentes transformadores, que consequentemente as causas são profundamente perceptíveis às pessoas com deficiências físicas e a todos os cuiabanos.

Evidenciado isso nos resultados, de forma que os profissionais ligados direta e indiretamente ao turismo, Instituições governamentais, não governamentais e a sociedade em modo geral, que a cidade de Cuiabá pode ser vislumbrada pelas pessoas com deficiências físicas de maneira inerente, mas pode ser evidenciada também, na construção de novos mecanismos para que a acessibilidade que todos têm por direito, mas poucos têm aos espaços urbanos, públicos e privados sejam de fato construídos e adequados não só porque é lei mais sim porque precisamos ter a liberdade de ir e vir a qualquer que seja o itinerário de partida e chegada, e que consigamos vivenciar ambientes mais igualitários a todas as pessoas.

\section{Geografia e Turismo}

A produção e reprodução espacial numa cidade se estabelecem por meio da sociedade e espaço geográfico, onde existe essa relação que se torna recorrente, 
acarretando muitas problemáticas, desafios, conflitos e contradições, e na cidade de Cuiabá isto não é diferente, acontece desde sua colonização e exploração aurífera.

A produção do espaço geográfico está diretamente ligada à sociedade, significa que o homem é o principal responsável por mudanças na [...] paisagem, região, espaço, lugar e território (CASTRO; GOMES; CORRÊA, 2000). Portanto o espaço enquanto reprodução das relações sociais de produção, a acessibilidade e o turismo, estão permanentemente articulados para que um se desenvolva, o outro deve estar em consonância.

(CARLOS, 2007) relata que [...] o acesso ao espaço na cidade está preso e submetido ao mercado no qual a propriedade privada do solo urbano aparece como condição do desenvolvimento do capitalismo. A existência da propriedade privada significa a divisão e parcelarização da cidade, bem como a profunda desigualdade do processo de produção do espaço urbano [...]. É neste contexto, de apropriação privada da terra, portanto, do espaço urbano que vamos investigar como é produzida a acessibilidade urbana e turística para as pessoas com deficiências físicas.

A maior parte das localidades turísticas consolidadas do mundo enquadra-se no primeiro caso, ou seja, existiam como cidades, antes do aparecimento do turismo em seu território. Isso se explica pelo fato de o fenômeno urbano ser muito anterior ao advento do turismo, como atividade econômica organizada, o que acontece somente no século XIX. (CRUZ. 2003. p.16).

O tipo de urbanização que se processa nesses casos - planejada ou não depende, em primeira instancia, da tomada de posição do poder publico local, ao qual - no caso brasileiro - é delegada a incumbência de orientar o desenvolvimento urbano no território do município. (CRUZ. 2003. p.17).

As desigualdades sociais se refletem no espaço urbano e as formas resultantes delas diferem em função de cada contexto específico. (VASCONCELOS. 2013. p.19).

Portanto é necessário refletir sobre o assunto, discutir e construir uma relação de mais igualdade por todas as pessoas seja ela com algum tipo de deficiência ou não.

\section{Turismo e um Novo Segmento}

O Turismo Inclusivo ou Turismo Acessível é um novo segmento que têm ganhado destaque, por atender as Pessoas com Deficiências - PCD's. Apesar de todo avanço no debate que permeiam as discussões sobre os direitos e acessibilidade das pessoas com deficiências, ainda é necessário ampliar a sensibilização do conhecimento ao assunto exposto e respeito da sociedade perante essas pessoas.

O Turismo é um fator socioeconômico de grande importância que intensifica e aperfeiçoa a mobilidade humana. Não existe praticamente lugar de nossa geografia onde não se observe a influência desse fenômeno em maior ou menor intensidade. Esses dois fenômenos, turismo e mobilidade, guardam uma relação direta e se influenciam mutuamente, ou dito de outra maneira, uma das formas mais importantes de mobilidade é o Turismo (BENI, 2006, p. 81).

Desta forma, diversos segmentos da atividade turística se desenvolveram, e vêm crescendo constantemente. Cada vez mais surgem práticas inovadoras como atender públicos com perfis diferenciados, como o do turismo inclusivo voltados às pessoas com deficiências. 
Turismo inclusivo ou turismo acessível é justamente voltado a todas as pessoas sejam jovens ou crianças, pessoas com deficiências físicas ou pessoas pertencentes a minorias étnicas, culturais e religiosas, tornam-se uma realidade a cada dia (TRIGO apud SILVA; BOIA, 2006, p. 13). Estes mesmos autores comentam que "essa é uma característica do turismo inclusivo: estar aberto a todas as pessoas, poder fornecer espaços físicos acessíveis e recursos humanos capacitados para atender às necessidades de todos os turistas".

A análise da cidade para definir hospitalidade, considera-se que, quanto maior a legibilidade, mais hospitaleira será facilitando o acesso de todos ao turismo, inclusive das mais diversas deficiências, sendo essa uma atitude essencial para garantir a integração da pessoa com deficiência ao ambiente em que ela se encontra e com os envolvidos no processo (GRINOVER apud MENDES; PAULA, 2007, p. 4).

Para que a pessoa com deficiência sinta-se pertencente àquela localidade deve estar preparado para receber esse visitante de modo a proporcionar-lhe maior interação com as atividades propostas e acesso aos equipamentos dispostos para o turismo.

\section{Pessoas com Deficiências - PCD’s}

A "deficiência" refere-se toda perda ou anormalidade de uma estrutura ou função psicológica ou anatômica, a incapacidade como toda restrição ou falta - devido a uma deficiência - da capacidade de realizar uma atividade na forma ou na medida em que se considera normal a um ser humano; e a desvantagem como uma situação prejudicial para determinado indivíduo, em consequência de uma deficiência ou uma incapacidade, que limita ou impede o desempenho de um papel que é normal em seu caso em função da idade, sexo e fatores sociais e culturais, (ORGANIZAÇÃO MUNDIAL DA SAÚDE apud MENDES; PAULA, 2007, p. 3).

De acordo com Censo do Instituto Brasileiro de Geografia e Estatística - IBGE, 2010 e a Organização Mundial da Saúde - OMS, no contexto da deficiência: no Mundo, a população total é de 7,0 bilhões de habitantes, cujo 10\% possuem alguma deficiência. No Brasil à população total é de 203,6 milhões de habitantes, segundo o Índice de Desenvolvimento Humano-IDH que é de 0,792 , totalizando $14,5 \%$ de pessoas que possuem alguma deficiência.

Cenário Nacional: Distribuição geográfica das pessoas com deficiência:

Gráfico 1: Porcentagem das pessoas com deficiências no Brasil, dividido por regiões socioeconômicas.

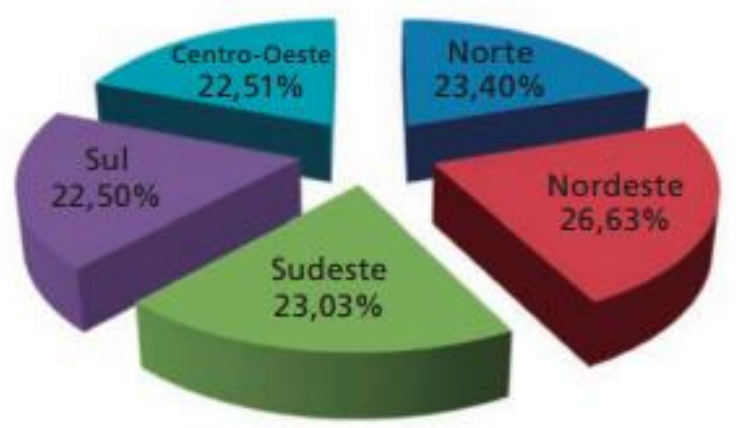

Fonte: Cartilha Censo 2010 - IBGE 
No gráfico acima é nítida a percepção como está distribuída a população de pessoas que possuem algum tipo de deficiência. Uma das características mais marcantes do ser humano é a diferença. Não existem duas pessoas iguais. É isso que torna cada indivíduo único. Encontra-se, dentre as "pessoas com deficiências", uma enorme heterogeneidade de diferenças advindas de vários tipos de déficits ou lesões físicas, sensoriais e mentais, que evidenciam o fato de não constituírem tais pessoas um grupo, um segmento ou outra denominação similar, quer do ponto de vista biológico, psicológico ou sociológico (MARCELLINO, 2003, p. 145).

Desta forma, a deficiência é uma dificuldade que as pessoas com deficiências sofrem pelo desconhecimento da sociedade, no que se refere às causas de como aquilo tenha ocorrido. Falta interesse da sociedade em conhecer as particularidades cotidianas dessas pessoas, para que não tenham um prejulgamento, assim ocasionando uma crítica infundada e discriminatória.

A deficiência deve ser reconhecida como capacidade restrita não desejada, e é importante que a consciência social a respeito deva se propagar na sociedade. A resolução do problema surgirá essencialmente das ações coletivas promovidas pelas várias frentes, sejam elas: individual, não governamental, pública e privada. Ação coletiva que concretamente se expressa no planejamento e nas ações social, setorial e multisetorial, em pesquisas científicas e tecnológicas, em campanhas de prevenção e tratamento, na construção de centros adequados, na legislação pertinente, na atuação associativa, na promoção de ajuda mútua, etc. (AGUIRRE, 2005, p. 35).

A deficiência não é algo que se deseja, porém, existem vários mecanismos para que isso se resolva e não seja mais um problema social, pois bastam ações enérgicas das pessoas com deficiências que se sentem excluídas e o poder público, para que, de fato, tenham uma qualidade de vida para efetivamente exercer todos os direitos de qualquer cidadão.

\section{Direito ao Lazer}

O direito é garantido por lei e assim, é justamente no setor do lazer que as pessoas com deficiências variadas enfrentam as maiores barreiras: arquitetônicas e de acessibilidade aos diversos espaços, como também as barreiras atitudinais presentes nas relações interpessoais, carregadas de preconceitos (MENDES; PAULA, 2008, p. 2).

O Art. $5^{\circ}$ da Constituição da República Federativa do Brasil trata dos direitos e deveres individuais e coletivos:

\footnotetext{
"Todos são iguais perante a lei, sem distinção de qualquer natureza, garantindo-se aos brasileiros e aos estrangeiros residentes no País a inviolabilidade do direito à vida, à liberdade, à igualdade, à segurança [...]".
}

O Art. 5ำ previsto no decreto-lei 5.296 de acessibilidade de 2 de dezembro de 2004, do capítulo II:

Os órgãos da administração pública direta, indireta e funcional, as empresas prestadoras de serviços públicos e as instituições financeiras deverão dispensar 
atendimento prioritário às pessoas portadoras de deficiência ou com mobilidade reduzida.

Leis 10.048 e 10.098 de 2000 disciplinam o atendimento prioritário e o direito à acessibilidade ao meio físico, aos transportes, à comunicação, à informação e às ajudas técnicas e de acordo com NBR 9050 DE 2004 - ABNT Associação Brasileira de Normas Técnicas - Acessibilidade de pessoas portadoras de deficiências a edificações, espaço, mobiliário e equipamentos urbanos (ACESSO BRASIL, 2004, p.n.p).

O lazer é essencial à vida humana equilibrada, saudável e produtiva. É indispensável à conservação e ao dinamismo regular do ecossistema humano, cujo ponto ideal de produtividade se manifesta nas atividades espontâneas e nas atitudes planificadas de expansão e de retração, de tensão e de relaxamento (ANDRADE, 2001, p. 21).

O turismo ainda é pensado como uma indústria mercadológica, onde o poder e o capitalismo estão em um patamar elevado contribuindo, assim, para a exclusão das pessoas com poder aquisitivo inferior a outros que têm como pagar pelo seu sonho de realização do lazer.

\section{Acessibilidade e Mobilidade}

De acordo com o decreto-lei 5.296 de acessibilidade de 2 de dezembro de 2004, do capítulo III art. 8ำ define:

A acessibilidade: condição para utilização, com segurança e autonomia, total ou assistida dos espaços, mobiliários e equipamentos urbanos, das edificações, dos serviços de transporte e dos dispositivos, sistemas e meios de comunicação e informação por pessoa portadora de deficiência ou com mobilidade reduzida (ACESSO BRASIL, 2004, p.n.p).

Percebe-se então, que existe uma lei a ser cumprida, para que haja o acesso nos locais de estrutura física e de comunicação entre as pessoas em que possam se locomover de forma segura e autônoma.

A mobilidade acarreta novas formas de vida que modificam as linhas conservadoras de comportamento. Pode também ampliar os horizontes culturais do indivíduo e injetar novo dinamismo à sociedade, ajudando a atingir de uma maneira rápida e eficiente objetivos de todo tipo, antes nem sequer suspeitados. A mobilidade, finalmente, põe em contato muitas pessoas, amplia e enriquece as maneiras de pensar e de atuar, expandindo o acervo cultural. Como todo fenômeno sociológico, é ambivalente, envolve elementos favoráveis e desfavoráveis (BENI, 2006, p. 80).

As pessoas mudam a todo tempo, seja no modo de agir, de pensar, conforme as coisas vão acontecendo o ser humano tende a tomar para si novas tendências que levam ao conhecimento de diversos assuntos debatidos socialmente.

Segundo Borja (apud CARVALHO; CARDOZO, 2008, p.5):

A acessibilidade e a mobilidade internas são requisitos indispensáveis para a competitividade da cidade como "meio econômico" e para que cumpra sua função de integração social. [...] Sobre esta base se realizam operações infra-estruturais e promocionais de caráter econômico: parques tecnológicos, recintos de exposição e congressos, áreas para empresas de serviços às empresas etc. Atualmente, tende-se a considerar os equipamentos culturais e turísticos também como de infra-estruturas econômicas, assim como integrar estes usos nas mesmas áreas do território. 
A acessibilidade é um fator imprescindível para a cidade, na visão não só de deslocamento, de chegada ou de saída, mas também na movimentação da economia local, assim aumentando consideravelmente os aspectos social, econômico e cultural.

\section{Considerações Finais}

Por meio das fotos do centro histórico de Cuiabá abaixo se percebe o maior descaso dos setores públicos responsáveis pelo planejamento e desenvolvimento da cidade de Cuiabá. Alguns locais ainda estão passando por reformas outros não. Carvalho (1989):

[...] nosso conhecimento do mundo físico e do mundo social se realiza a partir da observação espontânea, informal ou assistemática; registramos os fatos observados a partir da nossa experiência, cultura "visão de mundo", tentando buscar uma explicação para a realidade e as relações entre os fenômenos que a compõem.

Figura 1 Praça da Republica

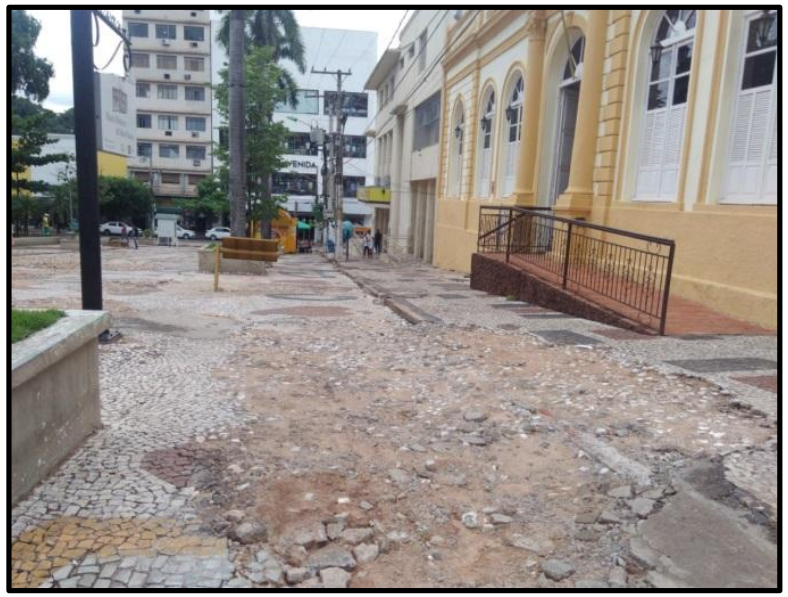

Fonte: Adriana Maria Rodrigues (2016)
Figura 2 Praça da Republica

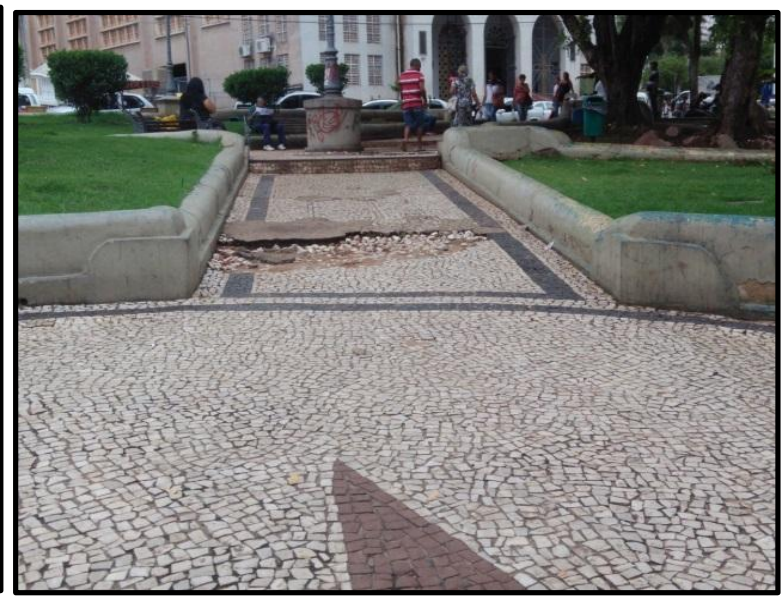

Fonte: Adriana Maria Rodrigues (2016)
Figura 3 Igreja Matriz

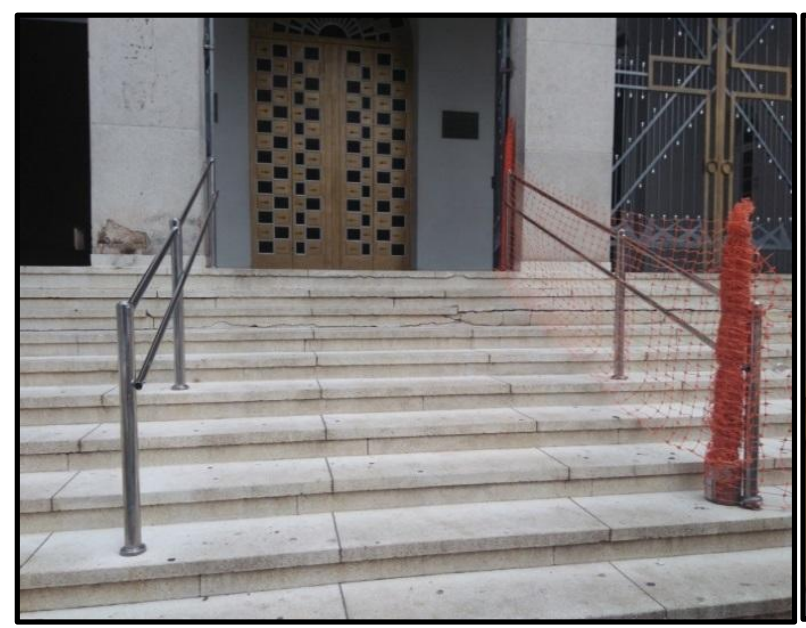

Fonte: Adriana Maria Rodrigues (2016)
Figura 4 Igreja Matriz

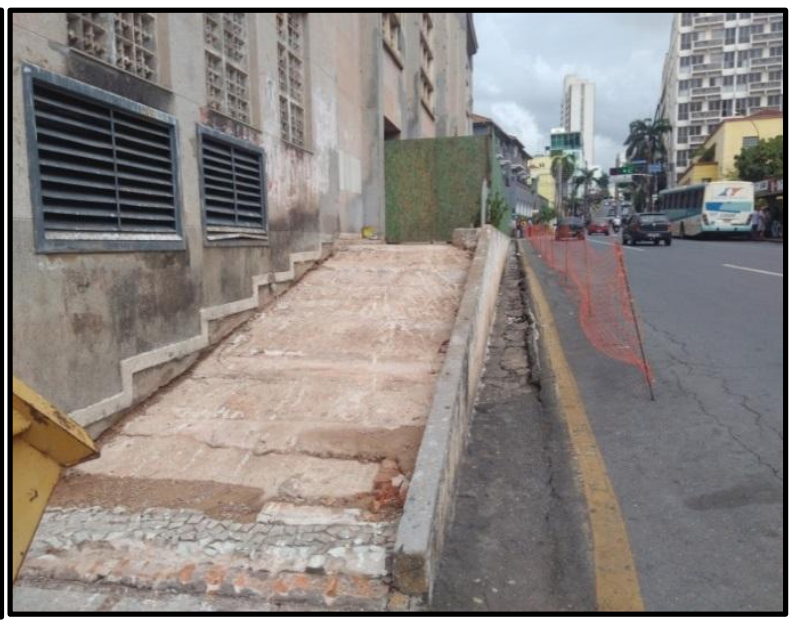

Fonte: Adriana Maria Rodrigues (2016) 
Reforça o que foi discutido ao longo deste artigo, na questão de produção do espaço urbano, sobre a acessibilidade e mobilidade, o direito ao lazer das pessoas sejam elas com algum tipo de deficiência ou não. Para tanto a de se responsabilizar os órgãos responsáveis por essa atribuição, temos o direito de ir e vir, por onde?

Como? Que a sociedade cobre mais e participe mais do que acontece ao seu redor, na sua cidade. Acredita-se que as melhorias acarretarão as pessoas desfrutar com maior autonomia, mais e os locais que nem se discuti isso? Precisam-se andar juntos em maior consonância, nos planejamentos, no desenvolvimento para a resolução do problema. Precisa-se de políticas públicas efetivas e participação das pessoas com deficiências físicas ou com qualquer mobilidade reduzida.

As cidades presentes foram, um dia, cidades do passado. Elas guardam, em sua intrincada rede urbana, elementos que as distinguem como parte da história dos povos milenares ou de acontecimentos memoráveis da ciência, da arte ou mesmo do esporte. O Brasil é um país novo e aberto para as diversas etnias que contribuíram para riqueza cultural que possuímos [...] (ARANHA; GUERRA, 2014).

Espera-se que algum dia os locais sejam aproveitados com maior consciência, respeito, dignidade, pois todos são responsáveis, têm direitos e deveres na convivência em sociedade, que os locais sejam adequados e construídos com acessibilidade, de forma apropriada a todos. Cuiabá está muito longe de ser considerada uma cidade acessível, mais não é impossível.

\section{Referências Bibliográficas}

ACESSO BRASIL. Lei de acessibilidade - decreto lei 5296. 2004. Disponível em: $<$ http://www.acessobrasil.org.br/ind. php?itemid=43>. Acesso em: 06 de julho de 2016.

AGUIRRE, R. Recreação e turismo para todos. São Paulo: EDUCS, 2005.

ANDRADE, José Vicente de. Lazer princípios, tipos e formas na vida e no trabalho. Belo Horizonte: Autêntica, 2001.

ARANHA, Raphael de Carvalho; GUERRA, Antonio José Teixeira. Geografia Aplicada ao Turismo. Organizadores - São Paulo: Oficina de Textos, 2014, Vários autores.

BENI, Mário Carlos. Análise estrutural do turismo. 11. ed. São Paulo: Editora Senac, 2006.

CARLOS, Ana Fani Alessandri. Espaço Urbano. 2. ed. São Paulo-SP: Labur Edições/GESP, 2007.

CARVALHO, Maria Cecília Maringoni (Org.) Metodologia científica: fundamentos e técnicas - construindo o saber. 2ª ed. Campinas: Papirus, 1989.

CARVALHO, Mariana Aldrigui; CARDOZO, Poliana Fabula. Planejamento das cidades e turismo: considerações sobre as questões sociais. In: SEMINÁRIO DA ASSOCIAÇÃO NACIONAL DE PESQUISA E PÓS-GRADUAÇÃO EM TURISMO, 5., 2008, Belo Horizonte. Anais. São Paulo: Aleph, 2008. 1 CD-ROM. 
CASTRO, Iná Elias; GOMES Paulo César Costa; CORRÊA, Roberto Lobato. (orgs.) Geografia: conceitos e temas. Rio de Janeiro: Bertrand Brasil, 2000.

CRUZ, Rita de Cássia Ariza da. Introdução à Geografia do Turismo. $2^{a}$ ed. São Paulo: Roca, 2003.

IBGE, População. 2010. Disponível em: <http://www.ibge.gov.br/população>. Acesso em: 04 de julho de 2016.

MARCELLINO, Nelson Carvalho. Formação e desenvolvimento de pessoal em lazer e esporte: para atuação em políticas públicas. Campinas: Papirus, 2003.

MARCONI, Marina de Andrade; LAKATOS, Eva Maria. Fundamentos de metodologia científica. 7a. Ed. - São Paulo: Atlas, 2010.

MENDES, Bruna C.; PAULA, Nilma Morcerf de. Uma análise sobre o mercado de turismo para pessoas com deficiência. In: SEMINÁRIO DA ASSOCIAÇÃO BRASILEIRA DE PESQUISA E PÓS-GRADUAÇÃO EM TURISMO, 4, 2007, São Paulo. Anais. São Paulo: Aleph, 2007, 1 CD-ROM.

MENDES, Bruna C.; PAULA, Nilma Morcerf de. A hospitalidade, o turismo e a inclusão social para cadeirantes. Disponível em: < http://www.143.107.93.222/ojs/index.php/turismo/article/view/14>. Acesso em: 2 ago. 2008.

PINHO, Raquel Tegon de. Cidade e loucura. Cuiabá-MT: Central de Texto: Ed UFMT, 2007. 147p.

SILVA, Yolanda Flores e; BOIA, Yolanda I. Keller. Turismo e responsabilidade social uma reflexão sobre os direitos das pessoas com necessidades especiais. In: RUSCHMANN, Doris V. de Meene; SOLHA, Karina T. (Orgs.) Planejamento turístico. Barueri: São Paulo: Manole, 2006, p.3-18.

VASCONCELLOS, Eduardo Alcântara. Transporte urbano, espaço e equidade: reflexões e propostas. $2^{a}$ ed São Paulo: Annablume, 2001.

VASCONCELOS, Pedro de Almeida; CORRÊA, Roberto Lobato; PINTAUDI, Silvana Maria. A Cidade Contemporânea: segregação espacial. (orgs). - São Paulo: Contexto, 2013.

VILARINHO, Cornélio Silvano Neto. Cuiabá, uma Metrópole Regional. In Novas Territorialidades Urbanas em Cuiabá, Sônia Regina Romancine (Org). Cuiabá: EdUFMT/FAPEMAT, 2008. 